Artigos 



\section{Histórias Cruzadas - considerações sobre uma nova modalidade baseada nos procedimentos relacionais}

José D’Assunção Barros*

Resumo: Este artigo objetiva discutir uma das mais recentes modalidades historiográficas que, ao lado da História Comparada e de outros campos como o da História Transnacional e o das Histórias Conectadas, defendem a proposta de lidar com "procedimentos relacionais" - aqui entendidos como aqueles que se encaminham para além das tradicionais abordagens historiográficas e atentam para os gestos historiográficos da comparação, do cruzamento, da interconexão e ultrapassagem dos limites nacionais e civilizacionais na escolha dos objetos historiográficos. A História Cruzada é essa modalidade enfatizada na parte principal do presente artigo, que considera que os procedimentos relacionais - entre os quais se enquadra o gesto historiográfico do "cruzamento" ou do "entrelaçamento" - podem se referir à definição do objeto de pesquisa, dos modos narrativos, procedimentos analíticos, cruzamento sistemático de fontes e outros aspectos da operação historiográfica.

Palavras-chave: Cruzamento. Entrelaçamento. Histórias Cruzadas. Procedimentos relacionais.

\footnotetext{
* Professor Adjunto da Universidade Federal Rural do Rio de Janeiro (UFRRJ), nos cursos de Graduação e Pós-Graduação em História e Professor-Colaborador do Programa de Pós-Graduação em História Comparada da UFRJ. Doutor em História pela Universidade Federal Fluminense. Doutor em História Social pela UFF. E-mail: jose.d.assun@globomail.com.
}

Anos 90, Porto Alegre, v. 21, n. 40, p. 277-310, dez. 2014 


\section{Introdução}

Há quase um século, a História Comparada surgiu na historiografia ocidental - a partir da proposta de Marc Bloch e de muitos outros historiadores no século $\mathrm{XX}^{1}$ - com vistas a ultrapassar certas $\infty$ limitações implicadas na tradicional historiografia ancorada em uma perspectiva nacionalista. Mais recentemente, as últimas décadas do século XX, e a passagem para o novo milênio, têm coroado com novas motivações esse já secular desenvolvimento da História Comparada, permitindo o surgimento de outras modalidades historiográficas emergentes que também lidam, de uma forma ou de outra, com 'procedimentos relacionais'. Assim, surgiram as possibilidades de desenvolvimento de outros gestos relacionais para além da comparação: a interconexão, o cruzamento, o entrelaçamento de histórias, de narrativas, de âmbitos de análise e de escalas de observação têm se afirmado com especial vigor a partir de novas propostas e modalidades historiográficas. Chamaremos a esses novos gestos que se juntam aos procedimentos da 'comparação', e que confrontam os fazeres historiográficos mais tradicionais, de "procedimentos relacionais", aqui utilizando uma expressão que encontramos pela primeira vez em Zimmerman e Werner (2002, p. 90).

Neste artigo, examinaremos uma das modalidades historiográficas mais recentes que, ao lado da História Comparada e das Histórias Conectadas, pode ser compreendida sob o abrigo do signo de uma história relacional: a História Cruzada. No item inicial, contudo, desenvolveremos um breve panorama de outras possibilidades que, de algum modo, aproximam-se da perspectiva da História Cruzada, ainda que definidas por suas próprias especificidades. Os campos históricos que discutiremos no primeiro item do artigo não correspondem, propriamente, apenas às Histórias Cruzadas, mas partilham com esta última modalidade a exploração de novos 'procedimentos relacionais', e por isso será útil situar antes de mais nada o conjunto de novas propostas relacionais que vieram se somar à História Comparada. A intenção principal do artigo é construir um balanço historiográfico, e uma explicitação das principais questões que envolvem, em um primeiro momento, as modalidades relacionais da história, e, em um segundo momento, o universo mais específico das Histórias Cruzadas.

Anos 90, Porto Alegre, v. 21, n. 40, p. 277-310, dez. 2014 


\section{As novas histórias baseadas em procedimentos relacionais}

As demandas por uma historiografia que sintonize com as necessidades planetárias, e a necessidade de repensar os limites do nacionalismo mais uma vez - tal como fizera Marc Bloch no período das guerras mundiais - levou alguns historiadores a questionar a eficiência da própria História Comparada no seu já antigo projeto de superar os limites da perspectiva nacionalista. Afinal, haviam se passado décadas, e muitos não viam resultados mais impactantes - e capazes efetivamente de redefinir as sensibilidades historiográficas correntes - na produção concreta dos historiadores comparatistas. Teria a História Comparada falhado no seu projeto inicial, e apenas redesenhado de uma nova maneira a história baseada nas cores nacionalistas? Se a resposta for positiva, como retomar mais seriamente esse projeto perdido? Autores como Serge Gruzinski quase parecem acusar o campo da História Comparada de ter dado uma volta sobre si mesma, e de ter se reconduzido aos parâmetros da historiografia tradicional:

A seleção dos objetos que têm de ser comparados, dos quadros e dos critérios, as perguntas, os mesmos modelos de interpretação, continuam sendo tributárias de filosofias ou de teorias da história que muitas vezes já contêm as respostas às questões do pesquisador. No pior dos casos, a história comparada pode aparecer como um ressurgimento insidioso do etnocentrismo (GRUZINSKI, 2001, p. 175-176).

“Comparar" não é uma operação simples. Não liberta automaticamente os historiadores das categorias e formas estereotipadas de pensamento que os amarram, das pressões que sobre eles se exercem. De fato, é possível elaborar uma História Comparada muito próxima à historiografia contra a qual ela mesma se insurgiu nos seus primórdios. Outrossim, é possível desenvolver uma História Comparada crítica, moderna, atualizada, sintonizada com novas metodologias e perspectivas conceituais. Novos caminhos, desse modo, têm surgido na família das Histórias Comparadas. Os

Anos 90, Porto Alegre, v. 21, n. 40, p. 277-310, dez. 2014 
olhares e recursos comparatistas aprimoram-se. Novas atitudes e possibilidades entram em cena. O historiador alemão Jürgen Kocka $(1941)^{2}$, um dos teóricos contemporâneos que mais têm refletido sobre os benefícios da História Comparada para esta nova etapa da história mundial, chama atenção, por exemplo, para a conexão da abordagem comparativa com correntes diversas de um novo campo que já vai sendo denominado História Global ou História Mundial:

Há, afortunadamente, muito interesse nos dias de hoje com relação às abordagens transnacionais para a História. As diferentes correntes de História Global ou História Mundial são um exemplo disso. Abordagens comparativas, comparações internacionais e interculturais, são apenas uma forma de perceber o crescente compromisso trans-nacional. Há outras formas, por exemplo, de estudos e interpretações usando teorias pós-coloniais (KOCKA, 2003, p. 42).

Entre as novas modalidades que têm surgido com vistas à transposição dos tradicionais limites nacionais ou regionais - e que, por assim dizer, alcançam o mundo de uma nova maneira têm se afirmado com especial vigor as "histórias interconectadas", "Histórias Cruzadas" e "histórias transnacionais". Estas definições ainda estão emergindo no seio do já vasto universo das designações de modalidades históricas, de modo que, por vezes, ainda apresentam certa ambiguidade quando confrontadas com a História Comparada, um campo bem mais definido, que lida com recortes mais precisos, embora múltiplos. Com a História Interconectada, pode-se dizer que o historiador escolhe se deixar ser conduzido criativamente pelo seu tema, o qual - além de eventualmente ser capaz de levar à transcendência das tradicionais fronteiras nacionais ou regionais - pode deslocar-se através de diferentes grupos sociais, identidades étnicas, definições de gênero, minorias, classes ou categorias profissionais. Certos temas prestam-se mais particularmente a este livre fluir historiográfico - a este surfar do historiador através das ondas de um grande mar no qual parecem ter se dissolvido todos os recortes tradicionais. 
As trocas culturais, no mundo midiatizado e globalizado, oferecem por exemplo um vasto leque de possibilidades de estudo às "histórias transnacionais". Sobre essa modalidade, a historiadora Micol Seigel ${ }^{3}$ assinala que a História Transnacional "[...] examina unidades que transbordam e vazam [infiltram-se] através de fronteiras nacionais, unidades que podem ser tanto maiores como menores do que o Estado-Nação" (2005, p. 62-90)4. Tampouco a História Transnacional deve ser confundida com a História Global, embora nada impeça a conexão entre as duas modalidades. Seigel tende a enxergar a História Global nos termos de um recorte (um espaço de observação) e a História Transnacional nos termos de uma abordagem, de uma atitude historiográfica. Os historiadores globais, diz-nos ela, uma vez definido o seu campo de interesses, têm diante de si a possibilidade de uma escolha entre a perspectiva transnacional e a perspectiva já tradicional da História Internacional:

\begin{abstract}
A História Transnacional não se propõe simplesmente a recobrir um maior espaço; ela não é equivalente a História Mundial - uma vez que os historiadores mundiais [historiadores globais], tal como todo mundo mais, precisam ainda escolher entre as abordagens transnacional ou internacional (SEIGEL, 2005, p. 63).
\end{abstract}

Ao mesmo tempo, os objetos da História Transnacional não se estendem necessariamente ao espaço ampliado que se torna típico da História Global. Assim, ainda que os historiadores globais assim definidos pelos seus objetos de estudo e territórios de observação historiográfica - possam optar pela abordagem da História Transnacional em desfavor da abordagem da História Internacional, há historiadores transnacionais cujo estudo pode perfeitamente se conformar em um território historiográfico situado entre limites nacionais, desde que o problema por eles examinados o levem a avaliar a interação entre o local e o global (os reflexos do global no local, por exemplo, ou mesmo o contrário): 
De fato, alguns adeptos do método transnacional tratam de fenômenos que recaem no interior de um único conjunto inserido no interior de fronteiras nacionais, revelando os traços do global no local (SEIGEL, 2005, p. 63).

A História Transnacional, desse modo, não se liga a uma aversão ao nacional. O seu desafio é enfrentar não o "nacional", mas a noção arraigada de que o "nacional" (ou um mundo dividido em nações como unidade de análise) deve ser a categoria predominante. Para a perspectiva transnacional de Micol Seigel, a nação apresenta-se como um fenômeno social que se situa ao lado de uma série de outros, "mais do que o quadro de estudos por si mesmo" (SEIGEL, 2005, p. 63). Ou seja, a nação pode ser perfeitamente estudada em uma perspectiva transnacional - e estudos transnacionais podem perfeitamente se apresentar no interior de fronteiras nacionais -, o que não pode ocorrer, para se ter uma perspectiva transnacional, é que a categoria da "nação" se apresente como a categoria central que conduz o pensamento historiográfico. A nação é algo a ser estudado; não é o quadro que emoldura o estudo como uma categoria a-histórica e incontornável.

Deborah Cohen ${ }^{5}$, por sua vez, acrescenta um elemento importante em sua busca de apreensão deste novo campo de possibilidades que seria o da História Transnacional, situando-o particularmente em confronto com o próprio campo da História Comparada. Segundo ela, enquanto a história comparada "[...] ocupa-se fundamentalmente das diferenças e semelhanças [...]" e frequentemente de "questões de causalidade", já as histórias transnacionais, em franco contraste com relação a esses aspectos, "[...] podem nos falar sobre circulação transnacional, história das trocas culturais, fenômenos internacionais" (COHEN, 2001, p. 24).

Não se trata mais, com as histórias transnacionais, e também com as histórias interconectadas e as Histórias Cruzadas, de meramente delimitar um certo número de recortes bem definidos, o que tem sido a operação central e a base de apoio das correntes da História Comparada que já vão se consolidando na sua forma mais tradicional. Pode-se mesmo dizer que há temáticas contemporâneas que já não se prestam a tais recortes. As redes sociais, por exemplo, 
os transcendem; as nacionalidades continuam a existir aqui como fenômenos de identidade, marcadores dos usuários, elementos instituidores de exclusão ou inclusão, mas o ambiente virtual já não conhece fronteiras, a não ser, eventualmente, a língua. O não lugar, instituído pela rede mundial de computadores através das redes sociais é apenas um exemplo. $\mathrm{O}$ mundo contemporâneo conhece também a formação de identidades diversas, que já não se definem nacionalmente. De igual maneira, a recepção de determinado produto - concreto ou virtual - atende a padrões de circulação que se perderiam se o historiador decidisse limitar o seu estudo a determinadas populações nacionalmente localizadas, regionalmente definidas em termos de uma visibilidade tradicional do espaço. O Cinema estende sua complexa malha para além dos seus sistemas localizados de produção. A Música possibilita formas de deslocamento diversas. Determinados circuitos constituídos necessariamente pela própria circularidade transnacional, inclusive para períodos mais recuados, rejeitam francamente a possibilidade de observância dos habituais recortes nacionais. É o caso da História Atlântica - esse domínio temático que implica um universo circular e intercontinental por definição $0^{6}$ - ou também dos estudos das "borderlands" [fronteiras], que inserem necessariamente o historiador em um complexo território de ambiguidades ${ }^{7}$. A história da diáspora negra, da mesma forma, implica a transnacionalidade ${ }^{8}$.

Ao lado da história transnacional, vale lembrar ainda que tanto este campo histórico como o das Histórias Cruzadas ou o das histórias entrelaçadas - dois outros domínios que já examinaremos - pressupõem possibilidades de mudanças no próprio estilo historiográfico (isto é, na maneira de escrever ou de expor os resultados da pesquisa). Possivelmente, essas e outras novas modalidades historiográficas têm muito a aprender com o romance moderno, com o Cinema e com outras práticas no que se refere aos novos modos de conduzir narrativas e as análises entrelaçadas. Elas também clamam por um novo padrão de leitura. As cartas estão colocadas, e o caleidoscópio historiográfico dá sinais de querer se movimentar mais uma vez.

Anos 90, Porto Alegre, v. 21, n. 40, p. 277-310, dez. 2014 


\section{Cruzamento, Entrelaçamento, Interconexão}

Além das perspectivas transnacionais, tem se afirmado nas últimas décadas outras modalidades historiográficas que se amparam nos chamados procedimentos relacionais - aqui entendidos como aqueles que se baseiam nos gestos operacionais do cruzamento, entrelaçamento e interconexão (sem mencionar o já tradicional gesto da 'comparação', que constitui a já mais antiga História Comparada). Se essas novas modalidades - a História Cruzada, as histórias entrelaçadas e as histórias interconectadas - constituem de fato um campo novo e diferenciado em relação à História Comparada - ou mesmo um espaço teórico-metodológico divergente em relação aos aportes comparatistas - esta é ainda uma discussão em curso. Micol Seigel, em seu artigo Além da Comparação, empenha-se em desenvolver a ideia de que a História Transnacional estaria em um campo divergente em relação à História Comparada. Refere-se, inclusive, a uma "virada transnacional" definidora de novos caminhos:

Esse ensaio atribui a virada transnacional às pesquisas anti e pós-colonialistas, e argumenta que este corpo de pensamentos contém uma crítica implícita ao método comparativo (SEIGEL, 2005, p. 62) ${ }^{9}$.

Por outro lado, se ampliarmos o sentido de comparação - ou se ao menos lidarmos com um sentido mais estrito para o comparativismo mais tradicional, que fixa de maneira mais rígida os recortes a serem dispostos em comparação, e com um sentido mais amplo, que considera a comparação como signo de uma família maior de "procedimentos relacionais" (uma expressão de Zimmermann e Werner) - poderemos pensar em uma família mais extensa de modalidades históricas que rompe com os recortes monocentrados da historiografia. A História Comparada, no sentido mais amplo de "História Relacional", representaria neste caso uma família de modalidades historiográficas que visam a libertar o historiador dos limites impostos pela obsessão da continuidade espacial e pelas ilusões de isolamento geopolítico, entre outras inúmeras travas que comprimem o habitual olhar historiográfico.

Anos 90, Porto Alegre, v. 21, n. 40, p. 277-310, dez. 2014 
É preciso se ter em conta, ainda, que pode haver maior proveito científico no agrupamento das modalidades relacionais do que na insistência em investir na fragmentação desta interessante família de campos historiográficos. Os "procedimentos relacionais" - comparatismo, interconexão, entrelaçamento, cruzamento, apreensão de dinâmicas transnacionais - podem perfeitamente encontrar abrigo nas linhas de pesquisa de laboratórios e associações de historiadores preocupados em não se deixar imobilizar pela rigidez dos recortes historiográficos tradicionais. Esses procedimentos relacionais, além do mais, podem se combinar, e não são necessariamente excludentes uns em relação aos outros. Na sequência deste artigo, trabalharemos com essa perspectiva, e, antes de nos aprofundarmos mais especificamente nas "Histórias Cruzadas", discutiremos o contexto destas novas designações.

É necessário reconhecer que, neste momento, em que parece estar ocorrendo um novo reajuste de possibilidades no universo historiográfico, é bem difícil prever quais das novas designações que têm surgido no cenário historiográfico - história global, história transnacional, histórias interconectadas, Histórias Cruzadas, entre outras - serão assimiladas efetivamente pelo vocabulário historiográfico com o qual passarão a lidar as futuras gerações de historiadores. As expressões podem desaparecer ou recuar do cenário principal tão rapidamente como surgiram. Algumas se consolidar-se-ão. Outras passarão para a história da historiografia. Quais, entre as designações de novas modalidades historiográficas, permanecerão no futuro vocabulário dos historiógrafos?

Tomando-se o gesto relacional da "interconexão", por exemplo, podemos dizer que a prática das histórias interconectadas envolve a possibilidade de religar experiências diversas de uma nova maneira, renovando o esforço que já havia sido realizado pela História Comparada mais tradicional no sentido de pensar novas possibilidades de recortes. A imagem de interconexão, por outro lado, remete tanto a possibilidades narrativas como a possíveis pontos problemáticos de conexão, sem mencionar que algumas realidades historiográficas complexas, como a dos grandes impérios que abarcam dentro de si mundos culturais diversos, parecem convidar ao estabelecimento de conexões com vistas a uma apreensão mais plena da realidade

Anos 90, Porto Alegre, v. 21, n. 40, p. 277-310, dez. 2014 
examinada. Nas histórias interconectadas, enfim, as histórias devem se encadear de alguma maneira.

A expressão "connected histories" - que para o Português adaptamos com a expressão "histórias interconectadas" - foi criada pelo historiador indiano Sanjay Subrahmanyam $(1961)^{10}$, estudioso do império português no período moderno. Segundo essa perspectiva, a História - ou "as" histórias - só podem ser, rigorosamente falando, múltiplas e diversificadas (ainda que interconectadas), e não constituem em absoluto uma única e grande História, homogênea, linear, conduzida em uma única direção. Serge Gruzinski ${ }^{11}$ assim descreve esse novo campo de possibilidades no que se refere às demandas que o geraram:

Diante de realidades que convém estudar a partir de múltiplas escalas, o historiador tem de se converter em uma espécie de eletricista encarregado de restabelecer as conexões internacionais e intercontinentais que as historiografias nacionais desligaram ou esconderam, bloqueando as suas respectivas fronteiras. As que dividem Portugal e Espanha são típicas: várias gerações de historiadores escavaram entre os dois países fossos tão profundos, que hoje em dia é preciso muito esforço para entender a história comum a estes dois países e impérios (GRUZINSKI, 2001, p. 176-177).

As histórias conectadas, ou "histórias interconectadas" como teremos liberdade de chamá-las - surgiram neste mesmo grande movimento que se tem construído em torno da sugestão de favorecer a ultrapassagem das fronteiras historiográficas artificiais. Não constituem necessariamente "histórias transnacionais", embora frequentemente também o sejam, no sentido de que o historiador é quem define o que estará “conectando". Por outro lado, certos objetos e problemas históricos, em decorrência de suas próprias características, quase demandam uma combinação entre histórias conectadas e história transnacional. Entrementes, as balizas nacionalistas, as categorias nacionais da atualidade e os direcionamentos estereotipados parecem pesar de tal maneira sobre a prática historiográfica em nossos dias que, mesmo diante da 
demanda de uma realidade histórica que já é multidiversificada por si mesma, os historiadores tendem a recuar para os limites tradicionais que mantém correspondências com o imaginário nacionalista ou com os recortes político-administrativos mais habituais. É o que nos diz Serge Gruzinski ao comentar a historiografia predominante nos estudos sobre a Monarquia Católica do início do período moderno:

Enquanto os historiadores costumam preocupar-se em inventar e construir novos objetos definindo territórios e cronologias, a Monarquia católica forma uma realidade preexistente no espaço e no tempo. Essa preexistência não significa [entretanto,] que os historiadores tenham espontaneamente adotado o território do império como campo de observação. Muitas vezes, esta realidade gigantesca, bastante heterogênea e fragmentada para se deixar facilmente estudar, foi escamoteada nas abordagens hispanocêntricas. O livro recente de Geoffrey Parker, The World is not enough. The Grand stategy of Philip II, apesar do seu título e das suas ambições, contém poucas coisas sobre as dimensões africanas, asiáticas e americanas da monarquia. Acontece o mesmo com abordagens italianas que não tomam em conta as Américas ibéricas, Portugal e Ásia nas suas reflexões sobre o 'sistema imperial' (GRUZINSKI, 2001, p. 179).

Dessa forma, mesmo diante dos objetos que expõem uma enorme riqueza de possibilidades já ao primeiro olhar, por vezes, deixam de ser percorridas fascinantes possibilidades de pesquisa e de tratamentos historiográficos fora da linearidade habitual ${ }^{12}$. As histórias interconectadas, assim como outras modalidades similares, requerem acima de tudo um rompimento em relação aos padrões historiográficos que costumam orientar as escolhas temáticas habituais, às quais uma boa parte da historiografia já se acostumou de modo demasiado rígido. Liberar o olhar historiográfico parece ser a sua pré-condição. Devemos ressaltar, ao lado disso, que existem pelo menos três modalidades (além das formas e experiências mais tradicionais de História Comparada) que se têm proposto a exercitar

Anos 90, Porto Alegre, v. 21, n. 40, p. 277-310, dez. 2014 
necessariamente esta liberação do olhar historiográfico, ao mesmo tempo em que desenvolvem uma abordagem historiográfica na qual se intensificam os "procedimentos relacionais"13.

Essas três modalidades, cujas designações parecem indicar campos históricos bastante próximos e com muitos pontos em comum, são as chamadas "histórias interconectadas", "histórias entrelaçadas" e "Histórias Cruzadas", sem mencionar uma outra modalidade que frequentemente se combina às três outras, e que tem sido denominada "história transnacional". Entrementes, a verdade é que parece haver uma certa disputa e territorialização, no campo de saberes contemporâneos, em torno dessas designações; nem sempre elas representam efetivamente experiências tão distintas, apesar dos manifestos que seus líderes procuram dirigir uns contra os outros à maneira de demarcar seus territórios acadêmicos. Como apresentam-se as novas modalidades relacionais no mapa dos atuais saberes historiográficos e de seus lugares institucionais? Reflitamos um pouco sobre isso.

As "histórias interconectadas" parecem tender a serem comumente assumidas como uma designação mais relacionada aos novos centros emergentes de produção do saber historiográfico - e não é à toa que a primeira vez que a expressão apareceu foi na obra de um historiador indiano. Outrossim, o historiador francês Serge Gruzinski (1949), pesquisador interessado em realidades culturalmente multidiversificadas como a do México antigo ou a do Império Hispano-Português, parece ter assumido essa mesma designação para alguns de seus trabalhos. Rigorosamente falando, o trabalho de Gruzinski sobre o Império Hispano-Português - ou sobre a Monarquia Católica - talvez pudesse se associar ainda com maior eficácia à designação das "histórias entrelaçadas", se considerarmos que o universo histórico por ele estudado abarca toda uma diversidade de realidades culturais e civilizacionais que passaram a se entrelaçar sob a orquestração dessa unidade política de extensões planetárias que foi a da União Ibérica. De todo modo, a possibilidade de transitar menos ou mais livremente entre as diversas designações apenas atesta a íntima proximidade dessas novas perspectivas de estudos.

Enquanto as "histórias interconectadas" têm se afirmado preferencialmente como designação historiográfica nos meios não

Anos 90, Porto Alegre, v. 21, n. 40, p. 277-310, dez. 2014 
europeus de produção do saber histórico, ou ao menos são encaminhadas por historiadores de qualquer parte que estão particularmente interessados nos contextos não europeus como objetos de estudo $^{14}$, a História Cruzada - outra designação que aponta para preocupações historiográficas muito próximas, a qual examinaremos em mais detalhes no próximo item - parece estar afirmando uma base sólida a partir de um grupo francês ligado à EHESS, em Paris $^{15}$. Por outro lado, também alguns historiadores vinculados a universidades britânicas e americanas, e mesmo germânicas, têm optado pela designação entangled history através de artigos, textos e autodefinições de seus próprios trabalhos ${ }^{16}$. Para fechar o circuito, podemos lembrar que as já discutidas "histórias transnacionais" apresentam uma grande recorrência, entre seus praticantes, de historiadores americanos. Existe, conforme pode-se entrever, uma certa oscilação de designações que nem sempre se refere, rigorosamente, a questões historiográficas específicas, e sim à sua inserção em certos centros, circuitos de historiadores ou laboratórios de pesquisa. Em seguida, examinaremos a modalidade historiográfica que é o principal objeto de interesse do presente artigo: A História Cruzada (ou Histórias Cruzadas).

\section{Histórias Cruzadas}

A noção de História Cruqada ${ }^{17}$, tal como a de 'histórias interconectadas', ainda oscila em torno de certas possibilidades de sentido. Trata-se de uma noção que ainda está se construindo no horizonte historiográfico mais recente. As motivações para o surgimento de uma perspectiva de História Cruzada remontam a contextos intelectuais diversos, como os debates sobre o Pós-Colonialismo ou a multiplicação de pesquisas que, a partir da perspectiva do Transculturalismo, procuram retomar a crítica do binômio Centro-Periferia e empenham-se em dar a perceber e examinar a fluidez das fronteiras que se estabelecem entre culturas diversas ${ }^{18}$. Entre as motivações para a emergência das Histórias Cruzadas também pode ser indicada a crescente necessidade de trabalhar de maneira mais complexa com a história de países que tiveram um passado em comum ligado por

Anos 90, Porto Alegre, v. 21, n. 40, p. 277-310, dez. 2014 
laços coloniais, bem como o interesse de disponibilizar aos historiadores a documentação relativa a esta história em comum que abarca diversificadas realidades nacionais. Certas temáticas de estudo, como o desenvolvimento histórico dos grandes circuitos continentais ou oceânicos (o Atlântico ou o Pacífico), bem como a "história das migrações", que produz evidentes emaranhamentos de etnias, realidades culturais diversas, identidades nacionais e interpenetrações religiosas, trouxeram a sua decisiva contribuição para o afloramento da necessidade historiográfica de se lançar mão, cada vez mais, do gesto relacional do "cruzamento". As temáticas contemporâneas surgidas com a globalização e a rede mundial de computadores, por fim, trouxeram sua especial contribuição para o crescente interesse de pensar a noção de "História Cruzada", a qual ainda vem sendo construída pela historiografia recente, não apresentando um único sentido. Bénédicte Zimmermann e Michael Werner ${ }^{19}$, em um artigo no qual procuram delimitar essas possibilidades de sentidos, assim se expressam acerca dos caminhos historiográficos que poderiam ser situados sob a designação de História Cruzada ou Histórias Cruzadas, no singular ou no plural, conforme o caso:

Empregada há cerca de dez anos em ciências humanas e sociais, esta noção deu lugar a vários usos. $\mathrm{Na}$ maioria dos casos ela remete, de modo vago, a uma ou a um conjunto de histórias, associadas à ideia de um cruzamento não especificado. Ela aponta então simplesmente para uma configuração de acontecimentos, mais ou menos estruturada pela metáfora do cruzamento. Frequentemente, aliás, tais usos evocam bistórias cruzadas, no plural. Este emprego corrente, relativamente indiferenciado, distancia-se das práticas de pesquisa que procuram uma abordagem mais específica. Neste caso, a história cruzada relaciona, geralmente em escala nacional, formações sociais, culturais e políticas, partindo da suposição que elas mantém relações entre si. Ela enseja por outro lado uma reflexão acerca da operação que consiste em 'cruzar', tanto no plano prático como no plano intelectual. Mas estes usos estão apenas começando a fixar-se (ZIMMERMANN; WERNER, 2003, p. 89-90). 
Os autores prosseguem mostrando que a História Cruzada se inscreve nessa família de campos históricos que foi inaugurada pela História Comparada há muitas décadas, a qual pode ser compreendida sob o signo dos "procedimentos relacionais", contando com a adesão de outros campos historiográficos mais recentes que, além da comparação, investiram nos "estudos de transferência"20, na elaboração das "histórias interconectadas" e na edificação de um campo que, em português, poderia ser traduzido como "história compartilhada" (Shared History) ${ }^{21}$. Por outro lado, há um empenho dos autores em captar a especificidade da História Cruzada. Entrementes, eles reúnem como aspectos formadores desta especificidade itens que, rigorosamente falando, não deveriam ser estranhos às corretas perspectivas comparatistas, ou mesmo à História em sentido mais amplo:

Mas a história cruzada ambiciona tratar objetos e problemáticas específicas que escapam às metodologias comparatistas e aos estudos de transferências. Ela permite apreender fenômenos inéditos a partir de quadros renovados de análise. Assim fazendo, ela fornece a ocasião de sondar, por um viés particular, questões gerais como escalas, categorias de análise, relação entre sincronia e diacronia, regimes de historicidade e de reflexividade. Enfim, ela coloca o problema da sua própria historicidade a partir de um triplo procedimento de historicização: do objeto, das categorias de análise e das relações entre o pesquisador e o objeto. Ela oferece, assim, uma 'caixa de ferramentas' que, mais além das ciências históricas, pode ser operacional em muitas outras disciplinas que cruzam as perspectivas do passado e do presente (ZIMMERMANN; WERNER, 2003, p. 90).

De resto, a "caixa de ferramentas" proposta por Zimmermann e Werner não deveria deixar de estar presente em todas as modalidades da família das histórias comparadas, ou mesmo na oficina do historiador, de modo geral. Outrossim, uma contribuição dos autores é chamar atenção para o fato de que determinadas categorias e escalas já tradicionais para a definição dos objetos da História Comparada como a região, o Estado-Nação, ou a civilização - precisam ser elas 
mesmas repensadas a partir da sua historicidade. Nenhuma dessas categorias é "unívoca ou generalizável", continuam os autores, mas sim “"...] carregadas de conteúdos específicos e, portanto, difíceis de transpor em quadros diferentes [...]”. De igual maneira, a escolha da escala nunca é neutra, "[...] mas sempre já marcada por uma representação particular que mobiliza categorias específicas historicamente constituídas" (ZIMERMMANN; WERNER, 2003, p. 92) 22.

Situados os problemas que desafiam as modalidades baseadas em "procedimentos relacionais", Zimmermann e Werner empenham-se em delimitar mais propriamente o que seria o campo da História Cruzada, segundo a sua proposta. "Cruzar", conforme salientam os autores, é "[...] dispor duas coisas sobre a outra em forma de cruz" (ZIMERMMANN; WERNER, 2003, p. 95). A imagem da cruz, efetivamente, permite em pensar pontos de intersecção entre as diversas realidades em cruzamento. Trata-se de uma imagem que também rompe com a perspectiva de linearidade que temos, por exemplo, com a imagem de um polo atuando sobre o outro que aparece mais comumente nos estudos de transferências culturais, que são criticados pelos autores como modelos que estabelecem pontos de partida e de chegada muito definidos. Os "pontos de intersecção" são lugares onde "[...] podem-se produzir acontecimentos suscetíveis de afetar em graus diversos os elementos em presença, segundo sua resistência, permeabilidade, maleabilidade, e de seu entorno". "Essa ideia de interseção", continuam os autores, “[...] está no princípio mesmo da história cruzada" (ZIMMERMANN; WERNER, 2003, p. 96).

A imagem de cruzamento também aparece de outra forma quando se pensa no entrelaçamento, e não é de se estranhar que também tenha surgido a designação de "histórias entrelaçadas" como mais uma alternativa entre as expressões que buscam nomear os modos de fazer história que concebem realidades ou processos que se interpenetram, que entram uns nos outros, que interagem de uma maneira tal que já não se mostra possível considerar cada unidade ou fio isoladamente.

Zimmermann e Werner atribuem um significado muito especial à ideia de cruzamento, e a situam no cerne de uma diferença patente entre a História Cruzada e a "história comparada" (expressão com 
a qual designam as práticas mais conservadoras e simplificadoras da História Comparada no sentido tradicional, em nossa opinião):

A noção de interseção exclui de início o raciocínio a partir de entidades individuais, consideradas exclusivamente por elas mesmas, sem ponto de referência exterior. Ela rompe com uma perspectiva unidimensional, simplificadora e homogeneizadora, em benefício de uma abordagem multidimensional que reconheça a pluralidade e as relações complexas que daí resultem. Desde logo, as entidades ou os objetos de pesquisa não são apenas considerados uns em relação com os outros, mas igualmente uns através dos outros, em termos de relações, interações, circulação. O princípio ativo e dinâmico do cruzamento aqui é primordial, em contraste com o quadro estático de comparação que tende a fixar os objetos (ZIMMERMANN; WERNER, 2003, p. 96).

Desde já, percebe-se que a proposta de História Cruzada encaminhada por Zimmermann e Werner se insurge contra aquelas práticas de História Comparada que recaíram em operações estabilizadoras, meras superposições de objetos ou realidades isoladas unidas por um liame de análise que, ainda que os unindo no interior de uma interpretação historiográfica, conserva-os separados. Depreende-se das propostas de Zimmermann e Werner a intenção de que não se perca o objetivo de conceber dois ou mais objetos em interação e com uma atenção redobrada aos modos como eles se modificam um ao outro, no caso das realidades sincrônicas que apresentam uma relação efetiva não apenas na imaginação do historiador ${ }^{23}$.

A demanda por uma especial atenção às interações, que se torna possível a partir do modelo das Histórias Cruzadas, e a concomitante crítica ao comparativismo tradicional como um modelo que costuma isolar os objetos em análise, também é encaminhada por Eliga H. Gould (2007) ${ }^{24}$. O historiador inglês - acompanhando um comentário de Jürgen Kocka (2003, p. 42) - ressalta que, “[...] mais do que insistir na comparabilidade de seus objetos ou na equalidade de tratamentos entre eles [...]", as Histórias Cruzadas estão preocupadas com as "influências mútuas", com as "percepções 
recíprocas ou assimétricas", com os processos entrelaçados que se "[...] constituem um ao outro" (GOULD, 2007, p. 766). Indo para além da percepção inicial de que certos universos históricos - como o Império Espanhol ou o Império Britânico do início da modernidade - praticamente impõem a necessidade da abordagem cruzada com vistas a favorecer a compreensão da sua multidiversificação interna, Gould sugere que "[...] longe de constituírem diferentes entidades, tal como os estudos comparativos usualmente sugerem, os dois impérios [Espanhol e Britânico] foram partes do mesmo sistema ou comunidade hemisférica" (GOULD, 2007, p. 765). Desse modo, o cruzamento no interior de uma realidade sincrônica é explorado aqui em toda a sua máxima extensão ${ }^{25}$. De resto, as experiências de construção de Histórias Cruzadas do Atlântico seguem adiante, produzindo inclusive perspectivas divergentes, como é o caso da proposta de Jorge Canizares-Esguerra (2007, p. 787-799) - historiador que critica a proposta de Gould e de outros pesquisadores a ele ligados em um artigo que traz um sugestivo título: Histórias Cruzadas: histórias de fronteiras em novas roupas? ${ }^{26}$. Retornemos, entrementes, às considerações de Zimmermann e Werner sobre a História Cruzada e suas implicações:

Cruzar é também entrecruzar, entrelaçar, ou seja, cruzar diversas vezes, segundo temporalidades eventualmente distanciadas. Este caráter pelo menos parcialmente processual é o terceiro aspecto constitutivo de uma problemática de cruzamentos. Ele nos remete à análise das resistências, das inércias, das modificações - das trajetórias, de formas, de conteúdos -, ou, de combinações que podem ora resultar do cruzamento, ora nele se desdobrar. Tais transformações, aliás, não se limitam necessariamente aos elementos postos em contacto; elas podem ainda tocar seu entorno próximo ou distante e manifestar-se segundo temporalidades distintas (ZIMMERMANN; WERNER, 2003, p. 96).

Situar elementos diversos em cruzamento, como ressaltam os dois autores, pressupõe considerar a natureza interativa de sua relação, evitando-se a perspectiva de que um polo influencia linearmente o 
outro, ou simplesmente transfere algo de si ao outro. As instâncias da "reciprocidade" ("[...] os dois elementos são afetados pela situação de relação [...]") e da "assimetria" (“[...] os elementos não são afetados da mesma forma [...]"), são indicados por Zimmermann e Werner como chaves de leitura fundamentais para a História Cruzada (2003, p. 97). Além disso, tal como já observamos para o caso das histórias interconectadas no item anterior, podemos considerar que os "cruzamentos" (ou o gesto historiográfico de cruzar) podem se dar em vários âmbitos diferenciados. Podemos fazer cruzamentos no momento de investigar ou analisar as realidades em estudo; e podemos cruzar "[...] os olhares e pontos de vista que se voltam para o objeto". Pode-se, por fim, conceber o cruzamento nos termos de "[...] relações entre o observador e o objeto, desencadeando assim uma problemática da reflexividade" (ZIMMERMANN; WERNER, 2003, p. 97). Dessa maneira, o cruzamento pode aparecer no próprio objeto de estudo (um tema que se presta essencialmente a isso ou um problema que é exatamente um cruzamento que teve lugar em um processo histórico ${ }^{27}$, como também pode aparecer ao nível das operações historiográficas mais propriamente relacionadas ao âmbito da pesquisa - seja no momento de delimitar o objeto de estudo, de investigá-lo, de problematizá-lo ou de analisá-lo. O cruzamento pode se configurar, ainda, nas operações narrativas e textuais que se destinam a expor os resultados da pesquisa sob a forma de um texto historiográfico específico. Em síntese, de um lado, o historiador pode pesquisar cruzamentos ${ }^{28}$; de outro lado, pode narrar ou elaborar o seu texto analítico lançando mão de um estilo cruzado (o autor-historiador pode alternar cruzadamente narrativas diversificadas, ou pode mesmo abrir espaço, em seu texto, para várias vozes que se entrecruzam, mostrando diversos pontos de vista e expressando-se consoante discursos distintos). São muitas as possibilidades, e poderíamos pensar, nesse sentido, em diversas submodalidades de "Histórias Cruzadas", considerando ainda que estas diversas submodalidades podem se combinar, sob a regência do historiador. Zimmermann e Werner mencionam ainda outra possibilidade: o "cruzamento de escalas". Como se sabe, a atenção para as diferentes escalas de observação ou de análise que podem ser utilizadas na operação historiográfica se intensificou a partir das últimas 
décadas do século XX, e em algumas correntes historiográficas, essa nova forma de consciência acerca do fazer historiográfico apresenta-se como "um problema de escolha do nível de análise pelo pesquisador” (ZIMMERMANN; WERNER, 2003, p. 102). A Micro-História, ao introduzir de forma pioneira a microescala no campo de possibilidades dos historiadores - no caso, por uma bem definida oposição às "macroescalas" da historiografia tradicional - constituiu a abordagem mais impactante entre as novas modalidades historiográficas que rediscutiram o problema da "escala" na produção do conhecimento histórico ${ }^{29}$.

Para utilizar uma metáfora conhecida, a Micro-História propõe-se a utilizar o "microscópio" ao invés do "telescópio" da historiografia tradicional (LEVI, 2003, p. 281). Ao olhar extensivo e abrangente desta última, que se alonga e se espraia na sua observação das realidades históricas examinadas, por vezes produzindo grandes generalizações e de resto buscando captar o grande conjunto, a Micro-História contrapõe o meticuloso olhar que busca captar elementos históricos essenciais, por vezes, pouco percebidos, através do "microrrecorte" - o qual pode ser uma trajetória de vida, uma vizinhança, certa prática social, uma pequena aldeia. Para evocar outra metáfora, a Micro-História propõe-se a enxergar algo do oceano inteiro a partir de uma bem escolhida gota d'água. Não se trata, contudo, de estudar o micro pelo micro, ou de estabelecer um recorte local por interesse específico no local. A proposta da MicroHistória é enxergar através do microrrecorte. Trata-se, conforme outra metáfora útil, de examinar a "enfermidade" através do micróbio, e não de investigar o micróbio por um interesse específico nos micro-organismos (LEVI, 2003, p. 281). A metáfora aplica-se à História: quando um historiador como Carlo Ginzburg resolveu seguir a tortuosa trajetória de Menocchio, um moleiro do século XVI que foi investigado e inquirido pela Inquisição, estava interessado não especificamente na vida de Menocchio, mas no que ela podia revelar em relação a certos problemas culturais que constituía o verdadeiro problema historiográfico de seu interesse. Através do processo inquisitorial que registra a meticulosa atividade dos inquisidores que investigam e interrogam Menocchio, Ginzburg (1976) consegue enxergar uma sociedade, um cotidiano, padrões culturais em circularidade. 
Com vistas ao seu objetivo de surpreender grandes questões históricas através do microrrecorte - ou, mais propriamente, da escala de observação reduzida - os micro-historiadores costumam tomar como fontes aquelas que permitem uma análise densa, que revelam muitos dos detalhes que mais habitualmente passam despercebidos da perspectiva macro-historiográfica tradicional. Os "processos criminais" e os "processos de Inquisição", entre muitas outras possibilidades de fontes, são exemplos de conjuntos documentais que atraem frequentemente a atenção dos micro-historiadores em vista da sua extraordinária riqueza de detalhes, das diversas vozes sociais que são perceptíveis nesse tipo de fontes, do olhar em microperspectiva com que o próprio investigador criminal ou o jurista costumam constituir essa espécie de documentação em sua própria época. Retornando a estes textos que um dia foram montados com o objetivo de investigar ou julgar seres humanos, os historiadores os retomam tempos depois com o fito de perceberem processos sociais, culturais e políticos que se revelam através de surpreendentes detalhes e de descrições densas e meticulosas.

Ocorre que, se a Micro-História trabalha com o "olhar micro", e a macro-história tradicional utiliza a tradicional escala ampliada, uma das possíveis submodalidades de Histórias Cruzadas organiza-se precisamente em torno da possibilidade de "cruzar escalas". Ao invés de fixar a sua escala única - "micro" ou "macro" - a História Cruzada investe na instigante possibilidade de trabalhar essas duas escalas, ou outras, em um ir-e-vir que pode se aplicar tanto ao trabalho de pesquisa como à exposição textual que é ofertada ao leitor do trabalho final produzido pelo historiador. Busca-se bem mais do que simplesmente alternar as escalas, considerando que este último caso poderia se dar, mais propriamente, em um trabalho de natureza multiscópica que, em um capítulo, desenvolvesse uma análise macro-historiográfica, e, em outro, elaborasse uma análise micro-historiográfica. Com a História Cruzada de escalas, para muito além disso, trata-se de pensar nas possibilidades mais inusitadas de entrelaçar escalas, contrapô-las, deixar que uma interaja sobre a outra - por vezes explorando mesmo as sutis tensões que se estabelecem entre a perspectiva que uma escala oferece e os aspectos que a outra escala permite ver ou ocultar. O 'cruzamento de escalas' constitui, 
desse modo, uma operação a mais no repertório de possibilidades que se abre com a História Cruzada. Ademais, tal como pontuam Zimmermann e Werner em sua crítica às três modalidades mais recentes que consideraram o "jogo de escalas" (micro-história, abordagem multiscópica, e alltagsgeschichte), estas parecem situar o problema das escalas apenas no âmbito de uma escolha teórico-metodológica.

A proposta de Zimmermann e Werner, outrossim, é chamar atenção também para "o problema da articulação empírica e do acoplamento de diferentes escalas ao nível do próprio objeto". As escalas, dessa maneira, seriam "[...] tanto um assunto de escolha intelectual, quanto induzidas pelas situações concretas de ação próprias aos objetos estudados". Certos objetos empíricos, dizem os autores, "[...] relevam de muitas escalas ao mesmo tempo e escapam a abordagens de foco único" (ZIMMERMANN; WERNER, 2003, p. 102$)^{30}$. Nesses casos, portanto, não se trata apenas de uma escolha teórica ou metodológica, mas de uma demanda que diz respeito ao próprio objeto de estudo, e que deve ser explorada adequadamente pelo historiador que se aproxima de sua complexidade. Por vezes, o entremeado multiescalar é indissociável de certos problemas, como parece ser o caso de boa parte dos estudos transnacionais, tal como sinalizam Zimmermann e Werner ao chamarem atenção para a sua "inextrincável imbricação":

Em uma perspectiva de história cruzada, o transnacional não pode simplesmente ser considerado como um nível suplementar de análise que viria somar-se ao local, regional ou nacional, segundo uma lógica de mudança de foco. Ele é, pelo contrário, apreendido enquanto um nível que se constitui em interação com os precedentes e que engendra lógicas próprias, com efeitos retroativos sobre as outras lógicas de estruturação do espaço. Longe de se limitar a um efeito de redução macroscópica, o estudo do transnacional faz aparecer uma rede de interrelações dinâmicas, cujos componentes são em parte definidos por meio dos vínculos que entretêm e das articulações que estruturam suas posições (ZIMMERMANN; WERNER, 2003, p. 102).

Anos 90, Porto Alegre, v. 21, n. 40, p. 277-310, dez. 2014 


\section{Considerações finais}

O gesto historiográfico do "cruzamento" - ou a consciência de que esta operação deve fazer parte do fazer historiográfico - parece ter conquistado o seu lugar epistemológico, enfim, no repertório de operações disponíveis aos historiadores contemporâneos. Com relação ao texto de Zimmermann e Werner - que às vezes passa da rica e meticulosa exposição teórico-metodológica ao manifesto que opõe a sua prática historiográfica a outras - podemos dizer que a História Cruzada é de certo modo apresentada, pelos autores, como forma historiográfica mais desenvolvida ou mesmo evolutiva em relação à História Comparada e aos estudos de transferências ${ }^{31}$. Isso porque os autores parecem dar a entender que a História Cruzada teria vindo para resolver certos impasses e limitações expressas pelas duas outras modalidades, já que no texto são contrapostos os gestos historiográficos do "cruzamento" ou da "comparação", com nítida crítica em relação ao último em decorrência da fixidez que a comparação parece impor ao objeto, ou como resultado da sua pretensa incapacidade - é o que dizem os autores - de perceber e dar a perceber as mudanças (este seria precisamente o "ponto cego" da comparação, segundo Zimmermann ${ }^{32}$.

De nossa parte, preferimos entrever como operações que não necessariamente se excluem os diversos gestos historiográficos surgidos a partir da emergência da família dos campos históricos que se baseiam nos "procedimentos relacionais", para retomar uma expressão de Zimmermann. Nesse sentido, "comparar", "interconectar", "cruzar", "entrelaçar", analisar "transferências" com a devida atenção às "reciprocidades" e "assimetrias" - estas e muitas outras operações devem fazer parte do metier dos historiadores nos tempos contemporâneos ${ }^{33}$. Deve-se também ter em vista que, se a história comparada pode ser compreendida em um sentido mais estrito, ela também pode ser evocada como uma instância mais ampla, na medida em que o gesto de comparar abre-se, de certo modo, a possibilidades diversas como o cruzamento e o entrelaçamento, ao lado da comparação mais tradicional. Nesse sentido, como proporemos mais adiante, a História Comparada também poderia ser evocada como

Anos 90, Porto Alegre, v. 21, n. 40, p. 277-310, dez. 2014 
uma família mais ampla que inclui diversos gêneros historiográficos, tais como "História Cruzada", "histórias entrelaçadas", "histórias interconectadas", "histórias transnacionais", "história global", além dos demais gêneros de história comparada que se afirmaram desde a primeira metade do século XX.

Podemos acrescentar, para concluir este artigo, que a designação "Histórias Cruzadas" também se abre para a possibilidade de se pensar em "historiografias cruzadas" - ou seja, de se investir no cruzamento de olhares historiográficos que quebrem a perspectiva do olhar eurocêntrico que por vezes contamina boa parte da historiografia tradicionalmente desenvolvida no Ocidente. Aqui, as Histórias Cruzadas dialogam com as possibilidades polifônicas de dar fluência a diversificados olhares historiográficos. Esse viés é particularmente importante quando pensamos na possibilidade de repensarmos leituras da história de outros continentes que não estejam orientadas pelo olhar europeu, ou que, pelo menos, incluam os outros olhares possíveis.

\section{ENTANGLED HISTORIES - CONSIDERATIONS ABOUT A NEW MODALITY BASED IN THE RELATIONAL PROCEDURES}

Abstract: This article intends to discuss one of the most recent historiographic modalities that, besides the comparative history and other historical fields as the transnational history and the connected histories, defends the proposal of deal with the 'relational procedures' - here understood as those ones that go beyond the traditional historiographical approaches and attempts to the historiographic gestures of comparison, entanglement, connection and overcoming of the national and civilizational limits in the choice of the historiografical subjects. The Entangled History is the modality emphasized in this article, which considers that the relational procedures - among these ones is situated the historiographic gesture of the entanglement - can be referring to the definition of the research subject, narrative ways, analytical procedures, systematic crossing of resources and other aspects of the historiographic operation.

Keywords: Entanglement. Interlacement. Entangled histories. Relational procedures.

Anos 90, Porto Alegre, v. 21, n. 40, p. 277-310, dez. 2014 


\section{José D’Assunção Barros}

\section{Notas}

${ }^{1}$ Algumas referências básicas de autores que explicitamente trabalharam com a noção de História Comparada - além de Block (1930) - podem ser atribuídas a Pirenne (1923), Tilly (1984), Detienne (2000), Kocka (2003). Jörn Rüsen, em um artigo específico, propõe aplicar a História Comparada ao estudo da Historiografia (2006, p. 115-138). Há ainda autores que, embora não delimitando especificamente um campo de História Comparada, desenvolveram claramente procedimentos comparativos que poderiam ser compreendidos como uma História Comparada, como é o caso de Max e Weber em seu estudo sobre os diversos tipos de cidade no tempo (WEBER, 1925), e Fernand Braudel em sua Gramática das Civilizações (1989). Um balanço sobre o surgimento da História Comparada pode ser encontrado em Haupt (1998, p. 205-216) e em Maier (1993, p. 11-32). No Brasil, a História Comparada encontrou expressão em algumas obras de Sérgio Buarque de Holanda, já desde a primeira metade do século XX (HOLANDA, 1936; 1969). 2 Jürgen Kocka - historiador alemão, professor e pesquisador no Centro de Pesquisas em Ciências Sociais de Berlim - é um dos líderes na Nova História Social Alemã (Bielefeld School). Além da perspectiva da História Comparada e da ênfase na História Social, seu acorde historiográfico traz a influência metodológica de Ernst Labrousse, historiador serial ligado aos Annales das duas primeiras gerações. Os estudos sobre as classes trabalhadoras e sobre a Industrialização são dois de seus principais interesses de estudo.

${ }^{3}$ Micol Seigel é professora e pesquisadora do Departamento de Estudos Americanos na Universidade de Bloomington. Seu artigo sobre a virada transnacional - Beyond Compare: Historical Method after the Transnational Turn - foi publicado em 2005, na Radical History Review.

${ }^{4}$ Ao indagar-se sobre a origem da História Transnacional, a autora contesta a ideia de que o contexto da globalização é o principal fator que impôs a demanda por uma história transnacional, preferindo sustentar a ideia de que a mesma decorre dos estudos anticolonialistas, já no pós-guerra, e da literatura pós-colonialista que se consolida nas três últimas décadas do século XX (SEIGEL, 2005, p. 63). Ao lado deste raciocínio, Micol Seigel sustenta ainda que o termo "história transnacional" deve ser contraposto à ideia de "História Internacional", uma linha que teria orientado a história diplomática e a história militar, entre outras. Com relação à História Comparada, Seigel assinala que a História Comparada tende a ser uma história internacional, e não transnacional (SEIGEL, 2005, p. 65).

${ }^{5}$ Deborah Cohen é professora e pesquisadora do Departamento de História da Northwestern University. Entre outros interesses historiográficos, tem escrito artigos relacionados à delimitação de alguns dos novos campos históricos que lidam com os procedimentos relacionais (COHEN, 2001, p. 57-70; COHEN, 2004, p. 9-23).

Anos 90, Porto Alegre, v. 21, n. 40, p. 277-310, dez. 2014 
${ }^{6}$ Para uma discussão sobre o conceito de História Atlântica, ver Baylin, 2005, e também Games, 2006, p.741-775. Para um conjunto de temáticas variadas sobre o Atlântico na História Global, ver o livro organizado por Seeman e CanizaresEsguerra (2007).

${ }^{7}$ Sobre as histórias de fronteiras (borderlands), estas têm se multiplicado nos EUA nas últimas décadas, em muitos casos, tematizando o modelo de expansão e formação territorial nos Estados Unidos. A título de exemplo, ver Weber (2000, p. 5-11), Johnson (2002, p. 259-271) e Citino (2001, p. 677-693).

${ }^{8}$ Robin Kelley (1999, p. 1045) identifica uma visão global sobre a diáspora já a partir dos estudos afro-americanos de fins do século XIX; neste sentido, a história da diáspora negra pode ser indicada como um dos primeiros domínios temáticos que teriam favorecido a perspectiva transnacional na História. Também Canizares-Esguerra (2007, p. 794) indica os historiadores da escravidão africana como os primeiros a constituírem uma historiografia do Atlântico.

${ }^{9}$ Esta posição aproxima-se à de Tyrrell, que assinala um certo fracasso da História Comparada em efetivamente ter "transcendido os limites da historiografia nacionalista” (TYRRELL, 1999, p. 1033).

${ }^{10}$ Sanjay Subrahmanyam (1961) - historiador indiano com interesses historiográficos no estudo do Império Português - é professor de História Indiana na Universidade da Califórnia. A História Econômica constitui um dos seus enfoques predominantes. Começa a se voltar para a abordagem das histórias conectadas em 2004, cunhando esta expressão em duas obras: Explorations in Connected History: From the Tagus to the Ganges (2004) e Explorations in Connected History: Mughals and Franks (2004).

${ }^{11}$ Serge Gruzinski (1949) - historiador francês especializado em temáticas latino-americanas, em especial no México colonial - também realizou pesquisas sobre o Brasil e o império hispânico-português do período moderno. O Pensamento Mestiço (original de 2001) é uma de suas mais conhecidas obras no Brasil. A sua ligação com o campo das histórias conectadas efetiva-se a partir dos seus mais recentes interesses pelo estudo da Monarquia Católica; segundo ele, um "vasto aglomerado planetário" que surge a partir de 1580, “quando a união das duas coroas [portuguesa e espanhola] acrescentou Portugal e o seu império mundial às posses de Carlos V" (GRUZINSKI, 2001, p. 179). Com esse objeto - uma vasta realidade política que conecta diferentes partes do planeta e diversificadas culturas - o império português/espanhol apresenta-se a Gruzinski como um lugar privilegiado para a prática de uma história simultaneamente interconectada e transnacional. De igual maneira, o fenômeno de planetarização recoberto pela Monarquia católica do século XVI pode ser observado em "âmbitos tão diversos como o urbanismo, a literatura e o direito” (GRUZINSKI, 2001, p. 181).

Anos 90, Porto Alegre, v. 21, n. 40, p. 277-310, dez. 2014 
${ }^{12}$ A Monarquia Católica pode ser entendida tanto como o império hispânico sob o reinado de Carlos V, dadas as suas vastas extensões que incluíram a Espanha, a América Hispânica, regiões da Itália, Áustria e Países Baixos, como também o momento posterior em que ocorre a União Ibérica entre Portugal e Espanha, a partir de 1580. Esta imensa e diversificada realidade política e cultural que foi a Monarquia Hispânica apresenta-se como um destes campos de estudos cuja fascinante complexidade se oferece ao historiador. Assim expressa-se Gruzinski a seu respeito: "A Monarquia católica é um objeto de investigação apaixonante. Recobre um espaço que reúne vários continentes; aproxima ou conecta várias formas de governo, de exploração e de organização social; confronta, de maneira às vezes bastante brutal, tradições religiosas totalmente distintas. Foi, ainda, o teatro de operações planetárias entre o Cristianismo, o Islão, e o que os ibéricos chamavam de idolatrias, uma categoria que abarca arbitrariamente os cultos americanos, os cultos africanos, ou ainda as grandes religiões da Ásia." (GRUZINSKI, 2001, p. 179-180). ${ }^{13}$ Estaremos aqui considerando as modalidades que atendem mais diretamente a necessidade de colocar em interação e de dar visibilidade às realidades sócio-históricas ou culturais que, por vezes, são indevidamente ofuscadas ou recobertas por uma história quase oficial (a qual privilegia apenas uma determinada realidade como se esta constituísse um caminho em pontilhado que quase se percorre sem a percepção de que se trata apenas de mais um caminho). É o caso, por exemplo, da leitura da civilização ocidental como única dimensão a ser estudada na Monarquia Católica, tal como observou Gruzinski no trecho anteriormente citado.

${ }^{14}$ Entre os historiadores que têm assumido a designação de "connected histories" para seus trabalhos há muitos voltados para os estudos sobre América Latina, África, Ásia. Para estes dois últimos casos, ocupam especial lugar os processos de descolonização. Ver, por exemplo, o livro Conectando Histórias: a descoloniz̧ação e a Guerra Fria no Sudeste Asiático, de Christopher E. Goscha e Christian F. Ostermann (2009). Ver ainda Hanifi (2011).

${ }^{15}$ École des Hautes études en sciences sociales.

${ }^{16}$ Apenas como exemplos, podemos citar algumas referências. A historiadora econômica americana Melissa Macauley, da Northwestern University, em conferência bem recente, intitula a sua pesquisa como "The Entangled History of the South China Sea: China, Southeast Asia, and Nineteenth-Century Counterinsurgency" (University of Harvard, 31 de outubro de 2013). No âmbito da conexão entre História e Relações Internacionais - outro universo temático que se abre adequadamente à prática da perspectiva da História Cruzada - o historiador alemão Reinhart Kössler tem operado com a designação, como no artigo Entangled History and Politics: Negotiating the Past between Namibia and Germany (2008), o que mostra a possibilidade do uso da perspectiva da História Cruzada para trabalhar a memória,

Anos 90, Porto Alegre, v. 21, n. 40, p. 277-310, dez. 2014 
a documentação e a história em comum produzidas nas interrelações entre países europeus e países africanos, americanos ou asiáticos que a eles estiveram vinculados por um passado colonial. Ainda na Alemanha, a designação Entangled History tem sido utilizada para designar linhas de pesquisa, como no Instituto para Estudos Latino-Americanos da Universidade Livre de Berlin (http://ning.it/1g3yI5p), ou como na Universidade de Zurich (http://ning.it/1g3AfbF). Já reportando ao universo acadêmico americano, Xiaoyuan Liu - historiador chinês residente nos Estados Unidos desde 1982 - utiliza-se da designação História Cruzada em um livro sobre a Independência da Mongólia no contexto da política territorial chinesa da primeira do século XX, no qual procura partir da inter-relação entre os dois países para iluminar questões mais amplas atinentes à história da Ásia no mesmo período (LIU, 2006).

${ }^{17}$ Histoire Croisée, em francês, expressão que tende a ser traduzida por Entangled History, em inglês. A palavra entangled, em seu sentido mais rigoroso, refere-se a emaranhado, ou a enredamento, mais do que a cruzamento).

${ }^{18}$ Ao passo em que o Multiculturalismo procura estabelecer fronteiras de reconhecimento entre as diversas culturas que coexistem em uma realidade social complexa ou em uma realidade política diversificada, o Transculturalismo direciona sua ênfase de estudos para a fluidez entre estas fronteiras. Essa perspectiva tende a se sintonizar com a ideia de "cruzamento", na História Cruzada, uma modalidade historiográfica na qual os contextos, problemas e possibilidades narrativas mais se entrelaçam do que se superpõem, a qual avança para muito além do mero reconhecimento de realidades culturais distintas sem considerar a sua interpenetração. ${ }^{19}$ Bénédicte Zimmermann é socióloga, historiadora e pesquisadora ligada a École dês Hautes études em sciences sociales e, além desta instituição, dirige também o Centre Georg Simmel. Michael Werner é historiador, professor e pesquisador de história cultural na École des Hautes études em sciences sociales.

${ }^{20}$ As relações entre Transferência Cultural e História Comparada mereceram um artigo específico de Mathias Middell (2000, p. 7-41). Um nome importante dos estudos de transferências é o de Michel Espagne (1952).

${ }^{21}$ A filosofia das "histórias compartilhadas" seria a mesma que ampara os projetos voltados para o exame do patrimônio comum entre as histórias de dois países que tiveram seu passado entrelaçado por algum liame muito forte, como é o caso das sociedades que estiveram ligadas por laços de colonialismo (caso de Brasil e Portugal, que mereceram o já mencionado Projeto Resgate, com vistas à disponibilização mútua de um patrimônio documental em comum). Ao mesmo tempo, podemos pensar em temáticas diversas que poderiam remeter a Shared Histories, como é o caso da história de minorias religiosas que, no interior de um país que possui uma forma religiosa dominante, partilham os mesmos processos de enfrentamento em relação aos mecanismos de repressão.

Anos 90, Porto Alegre, v. 21, n. 40, p. 277-310, dez. 2014 


\section{José D’Assunção Barros}

${ }^{22}$ É muito rico o universo de problemas levantados por Zimmermann e Werrner em seu artigo, o qual busca, de alguma maneira, estabelecer a História Cruzada em um espaço diferenciado em relação a outras modalidades como a História Comparada ou as Histórias Transnacionais. Entre os problemas a serem enfrentados pelas modalidades historiográficas, caracterizadas por "procedimentos relacionais", os autores lembram o problema das "zonas de contato", que se referem à interação que pode ocorrer entre os objetos de comparação: "Quando se estuda sociedades em contato, frequentemente constatamos que os objetos e práticas estão não somente em relação de inter-relação, mas ainda se modificam reciprocamente sob o efeito da relação estabelecida. Muitas vezes é o caso, por exemplo, nas ciências humanas e sociais, em que as disciplinas e escolas evoluem por meio de trocas cruzadas, em atividades culturais como a literatura, a música e as artes, ou em domínios práticos como a publicidade, as técnicas de marketing, as culturas de organização ou ainda as políticas sociais. O estudo comparado de tais zonas de contato, que se transformam enquanto interagem, convida o pesquisador a reorganizar seu quadro conceptual e a repesar seus instrumentos de análise" (ZIMMERMANN; WERNER, 2003, p. 93).

${ }^{23}$ A apreensão da mudança é uma instância fundamental do modelo de História Cruzada proposto por Zimmermann e Werner, que tendem a ver as experiências mais tradicionais de História Comparada como problemáticas em relação a suas potencialidades para apreender o que muda: "Mais do que um modelo analítico - que voltaria a fixar as coisas, justamente aqui, onde nós queremos, ao contrário, articular e colocar em movimento - ela, [a História Cruzada] oferece a possibilidade de organizar uma caixa de instrumentos que, reunindo os aportes metodológicos já testados da comparação e do estudo das transferências, permita apreender de modo mais satisfatório a complexidade de um mundo compósito e plural em movimento, e por aí mesmo a questão fundamental da mudança, ponto crítico ou mesmo cego da comparação e, em certa medida, das transferências" (ZIMMERMANN; WRNER, 2003, p. 97).

${ }^{24}$ Eliga H. Gould é professor na Universidade de New Hampshire e entre alguns dos seus principais temas de estudo estão a História Atlântica e a história da Revolução Americana. Entre suas principais obras, destacam-se: Entre os Poderes da Terra: a Revolução Americana e a constituição de um Novo Império Mundial (2012) e Persistência do Império (2000).

${ }^{25}$ Em algumas passagens de seu artigo Histórias Cruzadas, Mundos Cruzados, Gould também admite a designação "histórias conectadas", ao lado de "histórias cruzadas", para o estudo das interações entre o Império Britânico e o Império Espanhol (2007, p. 766).

${ }^{26}$ Jorge Canizares-Esguerra é historiador na Universidade do Texas, em Austin. Além de pesquisar a História do Atlântico, com uma relevante obra sobre História

Anos 90, Porto Alegre, v. 21, n. 40, p. 277-310, dez. 2014 
da Ciência no Império Ibérico (2006), um dos seus livros de maior destaque é Como Escrever a História do Novo Mundo? - bistórias, epistemologiase identidades no mundo atlantico setecentista (2002).

${ }^{27}$ De todo modo, é importante acompanhar os comentários de Zimmermann e Werner: "O cruzamento nunca se apresenta como um 'já dado ali' que bastaria identificar e registrar. Ele requer um observador ativo para construí-lo, e é num movimento de ida e volta entre o pesquisador e seu objeto que se desenham conjuntamente as dimensões empíricas e reflexivas da história cruzada. O cruzamento se dá assim como uma atividade cognitiva estruturante que, por diversas operações de enquadramento, constrói um espaço de compreensão" (2003, p. 97). De resto, a relação ativa entre o historiador e o seu objeto, segundo cremos, deve fazer parte da História em quaisquer das suas modalidades e combinações de modalidades.

${ }^{28}$ Zimmermann e Werner (2003, p. 98) dão como exemplo de pesquisa acerca de um cruzamento, ou de um problema histórico que é o próprio cruzamento, o ensaio de Sebastian Conrad sobre A Constituição da História Japonesa na confuência entre tradição local e importação de uma historiografia nacional europeia (CONRAD, 2003). Nesse caso, o historiador examina, além do próprio cruzamento, o momento anterior a este. O segundo exemplo apontado é o estudo realizado por Kapil Raj sobre os "efeitos do cruzamento entre métodos hindus e ingleses na gênese de uma cartografia britânica no começo do século XIX" (RAJ, 2003), em que o historiador examina "[...] o resultado de um vai e vem entre duas tradições distintas que se fecundaram" (ZIMMERMANN; WERNER, 2003, p. 98). Por fim, os autores mencionam o ensaio de Christine Labeau sobre os saberes administrativos do século XVIII, no qual demonstra como estes foram constituídos “[...] de maneira cruzada pela circulação, através de toda a Europa, de monografias e documentos de várias proveniências, conservados nos papéis privados dos gestores das finanças públicas da época" (ZIMMERMANN; WERNER, 2003, p. 99).

${ }^{29}$ Zimmermann e Werner mencionam, em seu artigo sobre a História Cruzada, três correntes da historiografia mais recente que têm estruturado suas propostas em torno da questão da escolha do nível de análise: a micro-história italiana, a abordagem multiscópica francesa e a Alltagsgeschichte alemã. Os autores procuram nuançar cada uma dessas propostas e, em alguma medida, situar-se criticamente em relação a elas, mas sem deixar de assimilar suas contribuições: “[...] a micro-história escolhe o micro para mostrar em que ele pode enriquecer e fazer evoluir as categorias utilizadas tradicionalmente pela análise macro. Seus adeptos mais radicais chegam até a trazer o conjunto de fenômenos a uma escala micro pela convicção de que o micro engendraria o macro. Já as propostas de abordagens multiscópicas desenvolvidas na França busca escapar a essa perspectiva dicotômica, concebendo os 'jogos de escala' como uma mudança de foco para variar

Anos 90, Porto Alegre, v. 21, n. 40, p. 277-310, dez. 2014 
os pontos de vista sobre o passado. Por esse princípio, o local aparece como uma 'modulação particular' do global e, ao mesmo tempo, como uma versão 'diferente' das realidades macro-sociais. Finalmente a Alltagsgeschichte fundamenta a escolha do micro e a crítica do macro numa antropologia das relações sociais" (ZIMMERMANN; WERNER, 2003, p. 101).

${ }^{30}$ Zimmermann traz como exemplo a sua própria pesquisa sobre a "constituição da categoria de desemprego na Alemanha entre 1890 e 1927", publicada em 2001: "Seus protagonistas [os desempregados e outros atores sociais envolvidos no problema do desemprego] agem simultânea ou sucessivamente em diferentes níveis: municipal, nacional, ou mesmo internacional, de tal modo que essas diferentes escalas aí se constituem em parte umas através das outras. As escalas não poderiam aqui ser reduzidas a um fator explicativo externo, pois são parte integrante da análise. Assim, de um ponto de vista espacial, elas remetem à pluralidade de cenas, de lógicas e de interações a que pertence o objeto de análise. De um ponto de vista temporal, elas colocam a questão das temporalidades do observador, do objeto e de suas interferências na confluência entre empina e metodologia. A atenção dada a seus acoplamentos e suas articulações permite dar conta de interações constitutivas de fenômenos complexos não redutíveis a modelos lineares" (ZIMMERMANN; WERNER, 2003, p. 102).

${ }^{31}$ É significativo o título do livro de Werner e Zimmermann no qual os mesmos expõem de maneira mais completa o seu projeto historiográfico. De la comparaison à l'histoire croisée, publicado em 2004, logo após o artigo de 2003, deixa entrever essa perspectiva de que a História Cruzada seria uma modalidade que se aperfeiçoa em relação à História Comparada e aos estudos de transferências.

${ }^{32} \mathrm{Em}$ algum momento, parece ocorrer uma mistura de critérios na exposição de Zimmermann e Werner. A História Comparada e a História Cruzada, de fato, podem ser consideradas como designações que se referem aos procedimentos, no caso, a "comparação" e o "cruzamento". Mas as "transferências" (ou os estudos de transferências) referem-se na verdade ao objeto de análise do historiador. Se é o historiador aquele que "compara", e que "cruza", não é ele quem "transfere". Ele "analisa transferências", na verdade. Dito de outra maneira, as transferências são o seu objeto nesta modalidade que tem sido situada sob o signo dos "estudos de transferências".

${ }^{33}$ Essa também parece ser a perspectiva de Roumen Daskalov e Tchavdar Marinov ao organizar o livro História Cruzada dos Bálcãs (2013). Ainda que incorporando a designação "Entangled History of Balkans", os autores buscam tratar a história moderna dos Bálcãs a partir de uma perspectiva simultaneamente transnacional e relacional que combina de formas diversas as histórias compartilhadas, interconectadas, cruzadas, sem esquecer as perspectivas da transferência e de outros tipos de cruzamentos.

Anos 90, Porto Alegre, v. 21, n. 40, p. 277-310, dez. 2014 
Histórias cruzadas - considerações sobre uma nova...

\section{Referências}

BAYLIN, B. Atlantic History: concept and contours. Cambridge, MA: Harvard University Press, 2005.

BLOCH, M. Comparaison. Bulletin du Centre International de Synthèse, n. 9, Paris, jun. 1930.

BRAUDEL, F. Gramática das Civilizações. São Paulo: Martins Fontes, 1989.

CANIZARES-ESGUERRA, J. Entangled Histories: Borderland Historiographies in new clothes?. American History Review, 112, n. 3, p. 787-799, 2007.

CITINO, N. J. The Global Frontier: Comparative History and the FrontierBorderlands Approach in American Foreign Relations. Diplomatic History, 25, n. 4, p. 677-693, 2001.

COHEN, D.; O'CONNOR, M. (Orgs.). Comparison and History: History in Cross-national perspective. N. Y./London: Routledge, 2004.

COHEN, D. Comparative History: buyer beware, GHI Bulletin, n. 29, inv. 2001. [também publicado em COHEN, D.; O'CONNOR, M. (Orgs.). Comparison and History: Europe in Cross - National Perspective. New York: Routledge, 2004. p. 57-70.].

Introduction: Comparative History, Cross - National History, Transnational History - From Theory to Practice. In: COHEN, D.; O'CONNOR, M. (Orgs.). Comparison and History: Europe in Cross - National Perspective. New York: Routledge, 2004. p. IX-XXIII.

CONRAD, S. La constitution de 1'histoire japonaise: Histoire comparée, histoire des transferts et interactions transnationales. In: ZIMMERMANN; WERNER. Histoire Croisée. Paris: EHESS, 2003.

DASKALOV, R.; MARINOV, T. Entangled Histories of the Balkans - volume I: National Ideologies and Language Policies. Bucharest: European Research Concil/Brill, 2013.

DETIENNE, M. Comparer l'incomparable. Paris: Seuil, 2000.

GAMES, A. Atlantic History: Definitions, Challenges, and Opportunities. American Historical Review, 111, n. 3, jun. 2006, p. 741-75.

GINZBURG, C. O queijo e os vermes: o cotidiano e as ideias de um moleiro perseguido pela inquisição. São Paulo: Companhia das Letras, 1998 [original: 1976].

GOSCHA, C.; OSTERMANN, C. Connecting Histories: Decolonization and the Cold War in Southeast Asia (1945-1962). Woodrow Wilson Center Press, 2009.

Anos 90, Porto Alegre, v. 21, n. 40, p. 277-310, dez. 2014 
GOULD, E. H. Entangled Histories, Entangled Words: the English-Speaking Atlantic as a Spanish Periphery. American Historical Review, june 2007. p. 765-786. GRUZINSKI, S. Os mundos misturados da monarquia católica e outras histórias conectadas. Topoi, p. 175-195, mar. 2001.

HAUPT, H-G. O lento surgimento de uma história comparada. In: BOUTIER, Jean; DOMINIQUE, Julia (Orgs.). Passados Recompostos: Campos e canteiros da História. Rio de Janeiro: Editora UFRJ/Editora FGV, 1998. p. 205-216.

HOLANDA, S. B. de. Raízes do Brasil. São Paulo: Companhia Brasileira de Letras, 1998 [original: 1936].

-Visão do Paraíso - os motivos edênicos no descobrimento e colonização do Brasil. São Paulo: Companhia Brasileira de Letras, 1995 [original: 1969].

JOHNSON, B. Engendering Nation and Race in the Borderlands. Latin American Research Review, 37, n. 1, p. 259-271, 2002.

KOCKA, J. Comparison and Beyond. In: History and Theory, n. 42, fev. 2003.

KÖSSLER, Reinhart. Entangled History and Politics: Negotiating the Past between Namíbia and Germany. Journal of Contemporary African Studies, n. 26, v. 3, p. 313-339, 2008.

LIU, Xiaoyuan. Reins of Liberation: An Entangled History of Mongolian Independence, Chinese Territoriality, and Great Power Hegemony (1911-1950). Stanford: Stanford University Press, 2006.

MAIER, C. S. La História Comparada, Studia Historica: historia contemporânea, v. X-XI, p. 11-32, 1992-1993.

MIDDELL, M. Kulturtransfer und historische Komparatistik, Thesen zu ihrem Verhãltnis [Transferência Cultural e História Comparada - teses sobre a sua relação], Comparativ, n. 10, p. 7-41, 2000.

PIRENNE, H. De La méthode comparative en histoire. In: DES MAREZ, G.; GANSHOF, F-L. (Orgs.). Compte-rendu du V Congrès des Sciences Historiques. Ghent: Weissenbrusch, 1923. p. 19-32.

RÜSEN, J. Historiografia Comparativa Intercultural. In: MALERBA, J. (Org.). A História Escrita. São Paulo: Contexto, 2006. p. 115-138.

SEEMAN, E. R.; CANIZARES-ESGUERRA, J. The Atlantic in Global History (1500-2000). Upper Saddle River (NJ): Pearson Prentice Hall, 2007.

SEIGEL, M. Beyond Compare: Comparative Method after the Transnational Turn. Radical History Review, n. 91, p. 62-90, Winter 2005. 
SUBRAHMANYAM, S. Connected Histories: Notes towards a Reconfiguration of Early Modern Eurasia. Modern Asian Studies, v. 31, n. 3, p. 735-762, jul. 1997. . Connected History: Explorations in Connected History - Mughals and Franks. Delhi: Oxford University Press, 2004.

. Connected History: From the Tagus to the Ganges. Delhi: Oxford University Press, 2004.

TILLY, Ch. Big Structures, Large Processes, Huge Comparisons. New York: Russell Sage Fondation, 1984.

TYRRELL, I. Making Nations/Making States: American Historians in the Context of Empire. Journal of American History, n. 86, p. 1033-1067, 1999.

WEBER, D. J. The Spanish Borderlands of North America: A Historiography. Magazine of History, n. 14, v. 4, p. 5-1, 2000.

WEBER, M. A Dominação Não-Legítima (Tipologia das Cidades). In: Economia e Sociedade. Brasília: UNB. v. II, p. 408-517, 1999. [original: post, 1925].

ZIMMERMANN, B; WERNER, M. Pensar a História Cruzada: entre empiria e reflexividade. Textos de História, v. 11, n. 1-2, p. 83-127, 2003. [original: Annales, jan./fev. 2003].

Recebido em: 30/08/2013

Aprovado em: 28/10/2013 